$\underline{\text { Article }}$

\title{
Innovation for Impact: An International Business Perspective on Transforming the United Nations
}

\author{
Katherine Tatarinov', Tina C. Ambos ${ }^{1}$ \\ 1 University of Geneva, Switzerland \\ Keywords: international organizations, technology, scaling, intrapreneurship, innovation \\ https://doi.org/10.46697/001c.31014
}

\section{AIB Insights}

Vol. 22, Issue 2, 2022

\begin{abstract}
While intrapreneurship and scaling are key themes in the International Business (IB) discussion, our research is the first to show how these concepts manifest in the context of the United Nations and how learnings from IB may be transferred. The United Nations (UN) organizations are tasked with solving the world's pressing and difficult problems. These organizations are major players in international governance and are characterized by bureaucratic, globally dispersed and politically driven structures, but are hardly ever considered in IB research. The UN organizations are struggling to create innovative approaches to fulfil their core missions in today's digital world and evidence shows that intrapreneurship and scaling innovation will be critical for transformation.
\end{abstract}

\section{INNOVATION IN THE UNITED NATIONS}

The United Nations (UN) - the world's only truly global organization- is tasked with solving the world's most pressing and difficult problems, such as conflict, poverty, and climate change. While its success is vital to all, the UN is often criticized for inefficiency, rigidity, and lack of adaptability. Innovation is an important way to respond to these critiques and bolster the UN in its mission. The UN will need to transform and build new capabilities and processes (Ambos $\&$ Tatarinov, 2021) and tap into diverse pockets of knowledge, collaborating both with country offices (subsidiaries) and other stakeholders, such as small and large businesses, governments, academia and non-governmental organizations (Bode, Rogan, \& Singh, 2019). Technology could play an important role as a connector between stakeholders but incorporating new tools and digitalizing processes is difficult when the UN is increasingly hampered with budget cuts, pressure for clear accountability to donors, and strained by the challenges of a changing technology environment (George, Howard-Grenville, Joshi, \& Tihanyi, 2016).

However, like private sector organizations, the UN struggles to embrace digitalization and its specific context creates further distinct challenges to innovation and change management. Core International Business (IB) themes such as innovation and organizational transformation have been studied in a variety of contexts, but to date, we have not considered how they apply to the UN and what we can learn from its attempts at transformation. The interesting case studies of innovation emerging from the UN can shed light on how international organizations with social missions successfully foster internal culture change, restructure towards agility, and develop collaborative cross-sector ecosystems. This article aims to position the context of the
UN as a comparative landscape for existing International Business (IB) theories around innovation and change.

\section{THE UNITED NATIONS AS A RESEARCH CONTEXT}

UN organizations, such as the World Food Programme (WFP) and United Nations Children's Fund (UNICEF), are large, complex entities that provide a rich context to study innovation, and in many ways overlap with multinational corporations (MNCs) as well as international non-profit organizations. They work globally - managing field offices (subsidiaries) in sometimes over 80 countries. They employ between 300 and 20,000 staff worldwide and retain large, centralized headquarters. The organizations are governed by executive boards consisting of member states which must vote on most decisions. While they receive their core funding from these member states, they must increasingly rely on additional financing from corporations and private donors. In short, the UN organizations (1) consist of many internationally dispersed units; (2) are non-for-profit, with rigid mandates and socially oriented missions; and (3) are based on political and bureaucratic procedures.

Although the governance structures, funding mechanisms and political interests distinguish these organizations from MNCs, some of their characteristics also involve core IB challenges. Two specific IB challenges are related to the creation and scaling of innovation. First, international dispersion and multiple hierarchical layers pose barriers for the creation of bottom-up innovation and change processes. Leading from the top responsibly while promoting innovation from the bottom is a key challenge for such large dispersed organizations (Ambos \& Tatarinov, 2021; Voegtlin \& Scherer, 2017). Second, when scaling innovation to vastly different institutional contexts, organizations face the classic standardization versus adaptation dilemma and 
Table 1. The Research Context of United Nations Organizations

\begin{tabular}{|c|c|c|}
\hline & $\begin{array}{l}\text { Intrapreneurship and Innovation in } \\
\text { MNCs }\end{array}$ & Intrapreneurship and Innovation in the United Nations \\
\hline \multicolumn{3}{|l|}{$\begin{array}{l}\text { Organizational } \\
\text { Characteristics }\end{array}$} \\
\hline Structure & Matrix or network-like & Centralized bureaucracy \\
\hline $\begin{array}{l}\text { HQ-subsidiary } \\
\text { relationships }\end{array}$ & $\begin{array}{l}\text { HQ owns and controls subsidiaries; } \\
\text { usually mixed-motive dyads with } \\
\text { coordination challenges }\end{array}$ & $\begin{array}{l}\text { HQ perceived as relatively powerless by field offices and } \\
\text { bottleneck for innovation; control by member states who } \\
\text { govern and fund the organization }\end{array}$ \\
\hline $\begin{array}{l}\text { Peer-unit } \\
\text { relationships }\end{array}$ & Often inter-unit competition & Usually collaborative due to mandatory staff rotation \\
\hline $\begin{array}{l}\text { Decision making } \\
\text { processes }\end{array}$ & $\begin{array}{l}\text { Top down with some bottom-up } \\
\text { elements }\end{array}$ & $\begin{array}{l}\text { Consensus based, political processes; slow moving and } \\
\text { hierarchical }\end{array}$ \\
\hline \multicolumn{3}{|l|}{$\begin{array}{l}\text { Innovation } \\
\text { Characteristics }\end{array}$} \\
\hline $\begin{array}{l}\text { Innovation } \\
\text { objectives }\end{array}$ & $\begin{array}{l}\text { Commercial: Competitive advantage, } \\
\text { economic gain }\end{array}$ & Social improvement; ability to serve organization's mission \\
\hline $\begin{array}{l}\text { Nature of } \\
\text { innovation }\end{array}$ & Private good & Public good character \\
\hline \multicolumn{3}{|l|}{ Environment } \\
\hline $\begin{array}{l}\text { Pressures for } \\
\text { Global Scaling }\end{array}$ & $\begin{array}{l}\text { Global standardization, economies of } \\
\text { scale }\end{array}$ & Globally intertwined grand challenges \\
\hline $\begin{array}{l}\text { Pressures for } \\
\text { Contextualization }\end{array}$ & $\begin{array}{l}\text { Adapt to differences in customer } \\
\text { needs, institutional differences) }\end{array}$ & $\begin{array}{l}\text { Strong field presence and understanding of beneficiaries } \\
\text { needs; include local players in project for greater impact and } \\
\text { sustainability }\end{array}$ \\
\hline \multicolumn{3}{|l|}{$\begin{array}{l}\text { Entrepreneurial } \\
\text { Processes }\end{array}$} \\
\hline $\begin{array}{l}\text { Resourcing of } \\
\text { innovation }\end{array}$ & Corporate funds & $\begin{array}{l}\text { Donor funds, partnerships - often not available for innovative } \\
\text { projects; need for different funding mechanisms }\end{array}$ \\
\hline $\begin{array}{l}\text { Incentives for } \\
\text { intrapreneurs }\end{array}$ & $\begin{array}{l}\text { Mandate extension, fiefdom-building, } \\
\text { seeking recognition from peers }\end{array}$ & Absence of organizational rewards \\
\hline $\begin{array}{l}\text { Role of } \\
\text { intrapreneurs }\end{array}$ & $\begin{array}{l}\text { Boundary breakers; seek } \\
\text { organizational recognition }\end{array}$ & $\begin{array}{l}\text { Socially-driven and entrepreneurial champions; seek } \\
\text { community recognition }\end{array}$ \\
\hline $\begin{array}{l}\text { Role of } \\
\text { innovation unit/ } \\
\text { team }\end{array}$ & Do innovation & Facilitate and support innovation \\
\hline Success metrics & $\begin{array}{l}\text { Profitability, competitive advantage, } \\
\text { growth }\end{array}$ & Social impact and policy changes, transparency \\
\hline
\end{tabular}

Source: Adapted from Ambos \& Tatarinov (2021)

consequently, coordination and control questions. Despite these parallels to MNCs and the central role the UN plays in international relations and global governance, IB research hardly ever focusses on this context nor on the transferability of management learnings to and from these organizations.

The key differences between the research context of intrapreneurship in the MNC and the UN are summarized in Table 1.

Our research addresses this issue by investigating how key IB phenomena, namely intrapreneurship and scaling innovation, manifest in the UN context. We spent four years collecting data on how innovation is developed, grows and scales within UN organizations. We found evidence for its contribution to organizational transformation and organizational learning that enables a capacity for further innovation (see also Ambos \& Tatarinov, 2019a, 2021). Several key applicable insights emerged around: (1) the nature of intrapreneurship, and (2) success factors for scaling (digital) innovations globally. These discussions provide managerial insights on how to incorporate innovation learnings from the periphery to the core organization and on enacting digital transformation by embracing cultural shifts.

\section{THE NATURE OF INTRAPRENEURSHIP IN THE UN}

Many notable commercial innovations, but also social innovations, originate in intrapreneurial activity (Burgelman, 1983), defined as entrepreneurship in large organizations. While the importance of intrapreneurship as a source of innovation is acknowledged in the for-profit context, the UN is only starting to explore the power of this concept. Despite the bureaucratic and hierarchical structures of the UN, which provide adverse conditions for entrepreneurial behavior, we found powerful examples of how intrapreneur- 
ship contributes to innovation outcomes, and ultimately fuels organizational transformation.

Through over forty interviews and several workshops with innovation leaders from thirteen UN organizations (such as the United Nations Development Programme, The United Nations High Commissioner for Refugees, or The World Food Programme), we created a database of 57 initiatives and 11 in-depth case studies that highlight how innovation is driven by intrapreneurship within these organizations. While "success" can be defined differently depending on the context, we define a successful initiative as one which emerges bottom up, is scalable, and delivers social impact. It is important to note, however, that the goal of innovation in the UN is not commercial success, but social improvement and the ability to serve the organization's mission. Innovative products or services, such as an AI-enabled chatbot that provides Q\&A to adolescents on challenging topics, mostly have public good character so that they are not "owned" by any organization but emerge in an ecosystem of partners.

It is no surprise that many intrapreneurial initiatives depend heavily on technology, particularly as they scale. According to innovators, technology is often the easiest part of the solution design: the harder and more critical parts are realizing the needs and tendencies of end-users and achieving impact targets. As Mima Stojanovic, former Innovation Portfolio Manager at International Committee of the Red Cross, explained: "The most difficult part is understanding the needs of the user and how to leverage, whether it is a technology, or a process, or a product, to meet those needs. And that has a lot more to do with the design and the conceptualization of the solution."

Our research found that resource reallocation is a mustwin-battle for intrapreneurial initiatives, particularly in a non-for-profit environment characterized by scarce resources and the absence of monetary returns. UN organizations primarily receive money from donors to fund activities related to the organizational mandate (such as alleviating hunger), not high-risk innovation activities. They operate in frugal environments, where potential failure is seen as irresponsible and misaligned with the goals of the organization. But this attitude stifles innovation, in which risktaking and failure are central principles. There is a new consensus among the UN top leadership that the organizations need to adopt a more innovation-friendly culture. Leading this shift throughout the entire organization is a difficult, yet critical, challenge for the UN.

\section{BRIDGING CONTEXTS: FROM CORPORATE INTRAPRENEURS TO UN CHANGE MAKERS}

Comparing intrapreneurship in the UN context to that of the private sector, we see a clear difference in three areas: in the incentives of the intrapreneurs, the breadth of stakeholders involved, and in the innovation governance structures. While in the private sector, intrapreneurs aim to achieve organizational recognition for their work; in the UN context, intrapreneurs shied away from attention. Instead, they were intrinsically driven to change the world and change the way their organizations help beneficiaries. Due to the UN's organizational culture of lengthy decisions and multiple gatekeepers, these innovators could often enact change by "doing first and asking later." Frequently many individuals became overwhelmed by stagnant environments and institutional bottlenecks and would leave their organizations. In the four years of our research, we saw several innovation teams fluctuate as team members changed.

In terms of stakeholders, we observed that in this context more than in the private sector, new project partners were brought in readily, which was instrumental to success. Project ownership was not often seen as a priority by the UN, but the tradeoff was that numerous stakeholders resulted in project management complexity and differences in resourcing capacity.

Finally, the governance structures and mandates of these organizations did not allow for straightforward approaches to innovation. Innovation units that emerged would often be positioned directly under the Director General (CEO), sitting outside the regular functional areas of the organization. Consequently, while these units are becoming more accepted, culturally they are frequently seen as non-relevant to the daily working processes of the organizations.

\section{HOW UN INNOVATIONS SCALE GLOBALLY}

IB research increasingly highlights the critical role of scaling in MNCs and international new ventures. It has recently also emphasized the role of digital technology (Monaghan, Tippmann, \& Coviello, 2020) and development contexts (Busch \& Barkema, 2020; Chliova \& Ringov, 2017). Scaling is equally critical for the UN to address the SDGs. The Grand Challenges, like climate change or poverty, are globally intertwined. And while UN organizations have the potential for global reach, solutions need to be deeply embedded in the cultural context of each country. Innovators often face institutional voids and rely on frugal means. In the past, UN organizations tried to scale innovations alone, reticent of entering partnerships in which they shared management. Today, cross-sector partnerships for sparking and resourcing innovation are key to successful scaling (Bode et al., 2019).

In the for-profit sector, the newness of a technology product or service can be a driver of value creation and standardization is often pursued. But in a context of diverse stakeholders and complex intertwined problems, a solution must be developed to address "wicked problems" that are locally embedded but globally intertwined. Our research shows that evolving ecosystems of actors are required when UN led innovation scales across different countries. In each location, a diverse set of partners work together to shape the best solution for the beneficiary.

We found that UN organizations who tapped into new resources from "non-traditional donors" were most successful in scaling innovation. Traditional donors are governments of member states, who provide the core budget for these organizations, and non-traditional donors are private sector MNCs, start-ups, and private individuals. We have seen many UN organizations drawing on new ways of financing innovation $^{1}$ and new partnerships to attract skills such as technological knowhow. Sometimes knowledge and capabilities were eventually brought in-house, establishing new 
centers of excellence - for example the H2Grow Platform that emerged at the World Food Programme after incorporating learnings from a hydroponic growing innovation.

To overcome rigid organizational processes, many UN organizations set up dedicated innovation units which would liaise with potential external partners and obtain new resources to enable innovative experiments. These partnerships can even have an impact on the operating logics of the UN. As Benjamin Kumpf, Head of Development Innovation Team at OECD, states, "The boundaries between inside and outside a [UN] organization or a government has locked the development and public sectors in configurations and mindsets that hinder their potential effectiveness. Tapping the potential of collective intelligence, of participatory and strategic foresight processes and of the fourth industrial revolution requires the design of new institutional arrangements" (Kumpf, 2018).

\section{LESSONS LEARNT}

The main insights from our study are that innovation can and does happen in bureaucratic, hierarchical organizations such as the UN, and that intrapreneurship is an equally powerful mechanism as found in the for-profit sector. However, the specific context of the UN must be considered (as outlined in Table 1) and insights from the UN may also be transferable to other non-profit organizations, especially those operating internationally. Our research surfaced the following topics, which bear a high potential for cross-sector learning:

1. Intrapreneurship is a powerful mechanism in all types of organizations. The initial motivation of the intrapreneur to pursue new ideas is critical - whether she is profit-driven or seeks to find a solution for poverty. In the UN, as in many other non-profit organizations, intrapreneurs need to navigate the tension between risk-averse organizations and their drive for social impact. To stimulate innovation, we encourage organizations with social goals to take a broader perspective on incentivizing intrapreneurs and reduce bottlenecks to enable faster organizational learning. Those innovations that were assisted in their scaling process by the headquarters imprinted new processes and ways of working on the rest of the organization resulting in transformational effects. Organizational barriers often follow in country-to-country innovation scaling patterns, without ever involving the organizational headquarters. This scaling also delivers social impact but does not deliver the full learning potential for the organization (see also Ambos \& Tatarinov, 2021). In the context of the MNC, this type of scaling would be hard to imagine. Consequently, we need to consider the power of coordination and control in different types of organizations.

2. Collaborative ecosystems are key to the realization of innovations driven by the UN, because UN orga- nizations often do not possess all resources and capabilities (e.g. technology) to drive innovation alone. This provides a particular challenge to digitalization (McLachlin, Tatarinov, Ambos, \& Puranam, 2021). Collaboration with private sector organizations is difficult due to the UN's need for transparency and strict reporting of all actions. Compared to the common view of business ecosystems (Iansiti \& Levien, 2004), which are usually built by buyer-supplier relationships around an anchor firm, ecosystems for social innovation are more versatile and stakeholders can take different roles in different countries (Ganco, Kapoor, \& Lee, 2020). Creating cross-sectoral ecosystems where different players have different social or profitdriven missions remains a challenge, and only ecosystems with a sustainable operating logic that caters to the demands of all partners will be successful. This insight also paves the way for how private sector organizations could work effectively with the UN - in collaborative global and local ecosystems orchestrated by the UN and aimed at scaling social innovation to new locations.

3. Another central insight of our research is on the nature of innovation units (Ambos \& Tatarinov, 2019b). While in the corporate world, innovation units mostly "do" research and development, UN innovation units rather facilitate innovation and coordinate capability development and learning across the organization. Unlike private sector R\&D or scouting units, UN units do not have clearly defined mandates and evolve their strategic orientations over time to fit the pressing goals of the organization. The nature of these units is not based on their tangible outputs such as products or processes, but on the relational value they are able to create for their organizations - amplifying learning from innovation and propelling cultural change.

In sum, this research paves the way for positioning the context of the UN organizations as a comparative landscape for existing IB theories around innovation and change. We hope to raise awareness to the managerial issues these organizations face as well as facilitate learning across disciplines to enable managers to foster and scale innovation in a way that is impactful and transformational.

\section{ABOUT THE AUTHORS}

Katherine Tatarinov (Katherine.tatarinov@unige.ch) is Postdoctoral Scholar and Research Director of the Center for Innovation \& Partnerships at the Geneva School for Economics and Management at the University of Geneva. Her research focuses on social innovation, digital transformation and managing the grand challenges. The United Nations organizations are her primary research context. Katherine lectures at Ecole Polytechnique Federale de Lau- 
sanne and is the Managing Director of the Geneva Innovation Movement Association, where she translates her research findings into applicable insights and community building.

Tina C. Ambos (Tina.ambos@unige.ch) is Professor of International Management and Director of the Center for Innovation \& Partnerships at the Geneva School for Economics and Management at the University of Geneva. Her research and teaching interests include global strategic management and innovation in the context of multinational corporations, technology start-ups and international (non-for-profit) organizations. She has published widely in the academic journals and is a regular speaker at international conferences and practitioner forums as well as leading executive programs.

Submitted: December 20, 2020 EDT, Accepted: August 22, 2021 EDT 


\section{REFERENCES}

Ambos, T. C., \& Tatarinov, K. 2019a. How innovation from within is transforming IOs as well as lives. World Economic Forum Agenda. World Economic Forum. https://www.weforum.org/agenda/2019/03/ho w-innovation-from-within-is-transforming-ios-as-w ell-as-lives/.

Ambos, T. C., \& Tatarinov, K. 2019b. SEED, SCALE, STRUCTURE: How International Organizations Shape Innovation. University of Geneva. https://inf o.gsem-exec.ch/seed-scale-structure.

Ambos, T. C., \& Tatarinov, K. 2021. Building Responsible Innovation in International Organizations through Intrapreneurship. Journal of Management Studies, 59(1): 92-125.

Bode, C., Rogan, M., \& Singh, J. 2019. Sustainable cross-sector collaboration: Building a global platform for social impact. Academy of Management Discoveries, 5(4): 396-414.

Burgelman, R. A. 1983. A model of the interaction of strategic behavior, corporate context, and the concept of strategy. Academy of Management Review, 8(1): $61-70$.

Busch, C., \& Barkema, H. 2020. From necessity to opportunity: Scaling bricolage across resource-constrained environments. Strategic Management Journal, 42(4): 741-773.

Chliova, M., \& Ringov, D. 2017. Scaling impact: Template development and replication at the base of the pyramid. Academy of Management Perspectives, 31(1): 44-62.
Ganco, M., Kapoor, R., \& Lee, G. K. 2020. From rugged landscapes to rugged ecosystems: Structure of interdependencies and firms' innovative search. Academy of Management Review, 45(3): 646-674.

George, G., Howard-Grenville, J., Joshi, A., \& Tihanyi, L. 2016. Understanding and tackling societal grand challenges through management research. Academy of Management Journal, 59(6): 1880-1895.

Iansiti, M., \& Levien, R. 2004. The keystone advantage: What the new dynamics of business ecosystems mean for strategy, innovation, and sustainability. Harvard Business Press.

Kumpf, B. 2018. Bottom-up, top-down and outsidein: Cultivating innovation at UNDP. Medium. http s://medium.com/@UNDP/bottom-up-top-down-andoutside-in-cultivating-innovation-at-undp-7d4935c5 6f9c.

McLachlin, R., Tatarinov, K., Ambos, T., \& Puranam, P. 2021. Embracing the New Frontier: Artificial Intelligence Initiatives in International

Organizations. University of Geneva. https://securese rvercdn.net/160.153.138.163/o31.95d.myftpupload.co m/wp-content/uploads/2021/06/AI_in_IOs_2021.pdf.

Monaghan, S., Tippmann, E., \& Coviello, N. 2020. Born digitals: Thoughts on their internationalization and a research agenda. Journal of International Business Studies, 51(1): 11-22.

Voegtlin, C., \& Scherer, A. G. 2017. Responsible innovation and the innovation of responsibility: Governing sustainable development in a globalized world. Journal of Business Ethics, 143(2): 227-243. 